\title{
Trends in Upper Tract Stone Disease in England: Evidence from the Hospital Episodes Statistics Database
}

\author{
Nicholas J. Rukin ${ }^{\mathrm{a}}$ Zain A. Siddiqui $^{\mathrm{b}}$ Edmund C.P. Chedgy ${ }^{\mathrm{c}}$ \\ Bhaskar K. Somanic

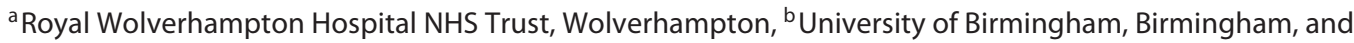 \\ 'Department of Urology, University Hospital Southampton NHS Trust, Southampton, UK
}

\section{Key Words}

Urolithiasis · Trend · Ureteroscopy · PCNL · Lithotripsy

\begin{abstract}
Aims: The study aimed to determine the current trends in urolithiasis-related admissions and associated interventions in England between 2006/2007 and 2013/2014 utilizing Hospital Episode Statistics (HES) online data. Material and Methods: Data was extracted from the online HES data set for each year from 2006/2007 to 2013/2014 inclusive. Admissions and procedural interventions were identified from their corresponding OPCS-4 and ICD-10 codes. Results: Finished consultant episodes (FCEs) for urolithiasis have increased by 20\% over the last 7 years, with 93,039 FCEs in the year 2013/2014. Based on English population statistics, the lifetime prevalence of urolithiasis based on hospital-related admission/intervention data for $2013 / 2014$ is $14 \%$. The biggest increases were seen in those aged $\geq 75$ years (up by $51 \%, n=$ $2,853)$. Total interventions have increased from 28,624 to 42,068 , with increased rates of shock wave lithotripsy (26\%),
\end{abstract}

\section{KARGER}

(C) 2016 S. Karger AG, Basel

E-Mail karger@karger.com

www.karger.com/uin ureteroscopy (URS; 86\%) and percutaneous nephrolithotomy (149\%). Emergency URS procedures have increased by $38 \%$. Day-case rates for ureteric and renal URS, in 2013/2014, were 22 and $21 \%$, respectively. Conclusions: Over the last 7 years, there is a rising prevalence of kidney stone disease with associated increase in the number of interventions related to it. Both elective and emergency URS procedures are increasing, with a rising trend for day-case URS. Similar trends are seen worldwide and future resource planning for urolithiasis is needed to match the increase in demand.

(c) 2016 S. Karger AG, Basel

\section{Introduction}

With a global incidence of around 10\%, urolithiasis and its management is becoming a major healthcare issue [1-5]. Technological advances have resulted in ever increasing treatment options, enabling us to achieve improved stone-free rates and offering our patients the best quality care. 
In England, the National Health Service (NHS) collects Hospital Episodes Statistic (HES) data that report on trends in English health utilization. Initially set up in 1987, HES data are reported on an annual basis. Classification of diseases (ICD-10) and surgical procedures and interventions are coded (using the OPCS-4) that is mandatory for admitted patient care commissioning data sets. Every hospital-related admission or procedure in England is coded in the secondary care setting, by an independently trained clinical coder. Data from each organization can then be collated nationally to derive the HES data set. HES data can be used for multiple purposes, including health resource planning, analysis of trends in admissions and interventional procedures, as well as future work force planning needs.

HES data are freely available online (http://www. hesonline.nhs.uk) and can be accessed, downloaded and analyzed independently via the website. In 2012, Turney et al. [2] reported on current trends in stone disease, utilizing English HES data over a 10-year period up to 2010. They reported increases in the prevalence and treatment of stone disease in England, concluding that such increases will have important implications for workforce planning, training, service delivery and research in the stone disease.

In the past few years, endourological advances and increasing sub-specialization have helped improve stone management for our patients. In view of the ever-increasing healthcare demands, limited financial funding and increased patient expectations, we believe it is imperative that we know the current trends in stone disease. Our aim is to update and further examine trends in kidney stone disease in England, using HES data, for disease prevalence and management.

\section{Methods}

All data were exported from the HES online data set (http:// www.hesonline.nhs.uk). Data were collected on a yearly basis, from $2006 / 2007$ to $2013 / 2014$, inclusive of a 7 -year period. The prevalence of stone-related admissions, using the ICD-10 diagnosis codes, was collected. Reported data relate to finished consultant episodes (FCEs). Using the OPCS-4 procedural codes, we were able to identify all stone-related procedures [6-10]. Data collected included the following: age, demographics, location and nature of the procedures, emergency workload, length of stay (LoS) and procedural day-case rates.

Extrapolating these data to population statistics gives an estimate of urolithiasis requiring FCEs in England. According to the Office of National Statistics, the mid-year estimate of the population in England was 51.0 million people in the year 2005 and
53.9 million in the year 2013 [3], representing a 6\% increase. This gives an annual prevalence of stone disease requiring a hospital visit of $0.153 \%$ in 2006 rising to $0.172 \%$ in 2013 . With an average life expectancy, across both sexes, of 79.7 years in 2005-2007 and of 81.25 years in 2012-2014 in England [4], this estimates an increase in the lifetime prevalence of urolithiasis from 12.19 to $13.98 \%$ over that time period. As these figures are based on coded hospital data, if stone-related community episodes are accounted, the lifetime prevalence is likely to be much higher.

\section{Results}

\section{Finished Consultant Episodes}

FCE for urolithiasis increased from 77,868 procedures in the year $2006 / 2007$ to 93,039 in the year $2013 / 2014$. This represents an increase in activity of $20 \%$ over the last 7 years. Across all age groups, except those less than 14 years, there was an increase in the total number of FCE. The percentage increase during these time periods was most significant in the $>75$ years age group $(51 \%$, from $5,611$ to 8,964$)$. FCE urolithiasis for $60-74$ years increased by $35 \%$ (from 16,777 to 22,644 ), while it increased by only $12 \%$ (from 55,007 to 61,310 ) for those of $15-59$ years. Meanwhile, the number of FCEs in those $<14$ years decreased marginally by $6 \%$ during the period of analysis.

Analysis of total interventions for urolithiasis per FCE including shock wave lithotripsy (SWL), percutaneous nephrolithotomy (PCNL), ureteroscopy (URS) and open surgery has demonstrated a significant increase too. In $2006 / 2007$, there were a total of 28,624 FCE interventions for urolithiasis in total; this figure increased to 42,068 in $2013 / 2014$, an increase of $47 \%$. Perhaps the most staggering increase was in the rates of PCNL that rose from 678 in $2006 / 2007$ to 1,687 in $2013 / 2014$, representing an increase of $149 \%$. It should be noted, however, that the PCNL rate increased from 678 in 2006/2007 to 1,209 in $2007 / 2008$ representing an increase of nearly $79 \%$ in 1 year. The number of open procedures for urolithiasis decreased by $38 \%$ (from 328 to 202) during the study period. Both SWL and URS demonstrated increases in FCE by 26 and $86 \%$, respectively.

Further sub-analysis of trends in SWL and URS, by location of stone, confirms an increasing trend across all modalities and locations. There was, in total, a $45 \%$ increase in SWL and URS for renal and ureteric stones from $2006 / 2007$ to $2013 / 2014$. Notably during the study period, interventions for renal stones using URS had increased from 2,597 in 2006/2007 to 6,048 in 2013/2014, an increase of $133 \%$. At the same time, SWL for ureteric
392

Urol Int 2017;98:391-396 DOI: $10.1159 / 000449510$
Rukin/Siddiqui/Chedgy/Somani 
Table 1. Number of patients for FCE, ureteric and kidney stone treatment modalities for 2006/2007 to 2013/2014 inclusive

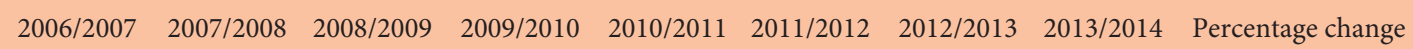
$(2006 / 2007-2013 / 2014)$

\begin{tabular}{|c|c|c|c|c|c|c|c|c|c|}
\hline \multicolumn{10}{|l|}{$\begin{array}{l}\text { FCE for 'urolithiasis', } \\
\text { years }\end{array}$} \\
\hline Total & 77,868 & 79,199 & 84,537 & 89,855 & 92,432 & 91,716 & 89,035 & 93,039 & 20 \\
\hline$<15$ & 464 & 467 & 470 & 519 & 422 & 436 & 491 & 437 & -6 \\
\hline $15-59$ & 55,007 & 54,740 & 57,473 & 61,239 & 62,276 & 60,468 & 59,029 & 61,310 & 12 \\
\hline $60-74$ & 16,777 & 17,905 & 19,603 & 20,789 & 21,729 & 22,455 & 21,392 & 22,644 & 35 \\
\hline$>75$ & 5,611 & 6,066 & 6,898 & 7,217 & 7,887 & 8,221 & 7,976 & 8,464 & 51 \\
\hline \multicolumn{10}{|l|}{ Ureteric stones } \\
\hline SWL & 3,130 & 3,070 & 2,760 & 3,038 & 3,150 & 3,345 & 2,922 & 3,307 & 6 \\
\hline URS & 6,327 & 6,822 & 8,004 & 8,773 & 9,358 & 9,859 & 10,338 & 10,562 & 67 \\
\hline Emergency URS & 954 & 906 & 1,003 & 1,092 & 1,165 & 1,221 & 1,313 & 1,268 & 33 \\
\hline Day case URS & 640 & 713 & 1,015 & 1,073 & 1,325 & 1,699 & 2,013 & 2,328 & 264 \\
\hline \multicolumn{10}{|l|}{ Kidney stones } \\
\hline SWL & 15,564 & 16,279 & 18,684 & 19,352 & 19,926 & 19,913 & 19,546 & 20,262 & 30 \\
\hline URS & 2,597 & 2,704 & 2,842 & 3,267 & 4,085 & 4,618 & 5,315 & 6,048 & 133 \\
\hline Emergency URS & 94 & 73 & 89 & 90 & 133 & 143 & 141 & 179 & 90 \\
\hline Day case URS & 197 & 339 & 350 & 336 & 410 & 662 & 894 & 1,245 & 531 \\
\hline \multicolumn{10}{|c|}{$\begin{array}{l}\text { Combined ureteric and } \\
\text { kidney stones }\end{array}$} \\
\hline SWL & 18,694 & 19,349 & 21,444 & 22,390 & 23,076 & 23,258 & 22,468 & 23,569 & 26 \\
\hline URS & 8,924 & 9,526 & 10,846 & 12,040 & 13,443 & 14,477 & 15,653 & 16,610 & 86 \\
\hline PCNL & 678 & 1,209 & 1,450 & 1,732 & 1,689 & 1,806 & 1,875 & 1,687 & 149 \\
\hline Open stone removal & 328 & 231 & 181 & 147 & 155 & 188 & 182 & 202 & -38 \\
\hline
\end{tabular}

Table 2. Day case rates for URS from $2006 / 2007$ to $2013 / 2014$

\begin{tabular}{|c|c|c|c|c|c|c|}
\hline & \multicolumn{2}{|c|}{$2006 / 2007$} & \multicolumn{2}{|c|}{$2013 / 2014$} & \multirow{2}{*}{$\begin{array}{l}\text { Change in day-case } \\
\text { rates }(2006 / 2007 \text { to } \\
2013 / 2014), \%\end{array}$} & \multirow{2}{*}{$\begin{array}{l}\text { Increased from } \\
2006 / 2007 \text { to } \\
2013 / 2014 \text { by }\end{array}$} \\
\hline & number & $\begin{array}{l}\text { proportion } \\
\text { day-case, } \%\end{array}$ & number & $\begin{array}{l}\text { proportion } \\
\text { day-case, } \%\end{array}$ & & \\
\hline Ureteric & 640 & 10 & 2,328 & 22 & 264 & $\times 3.6$ times \\
\hline Kidney & 197 & 7.5 & 1,245 & 21 & 531 & $\times 6.3$ times \\
\hline
\end{tabular}

stones remained relatively static when taking the population variance into account, which rose marginally from 3,130 to 3,307 ( $6 \%$ increase) during the time period. In contrast, ureteric URS increased by $67 \%$.

Analysis of emergency procedures for urolithiasis confirms the commonest intervention to be ureteric URS, with ureteric SWL and renal URS also prevalent but at much lower rates (table 1). The total number of emergency ureteroscopic interventions increased by $38 \%$ from 1,048 in $2006 / 2007$ to 1,447 in $2013 / 2014$, the highest total number of interventions to date. Renal URS showed the most significant rate of rise with a $90 \%$ increase in procedures. However, it should be noted that they accounted for only $15 \%$ of all emergency ureteroscopic procedures in the year 2013/2014.

Trends in Upper Tract Stone Disease

\section{Length of Stay}

Throughout the time period, the median overall LoS for URS and PCNL have decreased by an average of 36\%. Interestingly, the LoS for PCNL decreased from 5 to 4 days between 2006/2007 and 2007/2008 and has stayed consistently at 4 days since. Ureteric and renal URS LoS have decreased from 2.21 to 1.17 and 4.33 to 2.25 days, respectively (47 and $48 \%$ decrease LoS). This is largely due to the almost exponential increase in day-case procedures for both renal and ureteric URS.

\section{Day-Case URS}

The rate of day-case ureteric URS increased 3-fold, while the rate of day-case renal URS increased by over 6 -fold (table 2). Despite such increases in day-case rates,

Urol Int 2017;98:391-396 DOI: $10.1159 / 000449510$ 
it must be noted that for the most recent year (2013/2014), the day-case rate for renal URS was only $21 \%$ and for ureteric URS was $22 \%$.

\section{Discussion}

\section{Findings of Our Study}

Trends of Urolithiasis and Interventions

Our data demonstrate that there has been a significant increase in FCEs as a result of urolithiasis. Certainly, the lifetime prevalence of urolithiasis has historically been reported at $10 \%$ [2]; these current data put that figure at closer to $14 \%$, meaning roughly 1 in 7 of the population will require a hospital-based intervention for urolithiasis. Similar trends of increased intervention for urolithiasis has also been demonstrated in a Canada-based study, which demonstrated a $48 \%$ increase in patients undergoing kidney stone procedures between 1991 and 2010 [11]. It must be noted that the prevalence data are based on FCEs, and one patient may have had multiple FCEs over a year and therefore, these estimates will vary. The increasing prevalence of urolithiasis is likely to be a result of increased prevalence in obesity, associated metabolic syndrome and type 2 diabetes [12]. The increasing age of patients presenting with stones, as well as the postulated underlying causes of obesity, and the metabolic syndrome pose significant problems for those commissioning healthcare. Whilst no costing analysis has been performed for this paper, there is clearly a significant and growing challenge to the provision of care for patients with urolithiasis both in terms of health expenditure and resource utilization.

Interestingly, in our study, the most significant rate of rise in FCEs for urolithiasis occurred in the $>75$ years age group ( $51 \%$ increase) over the study period. This was also demonstrated in an American study, reporting significantly increased hospital admissions for stones in older patients [13]. Certainly, this contradicts the classical teaching that stone disease affects the young and middle aged. This may have significant clinical and resource implications, particularly with an aging population. A recent analysis in the US has demonstrated an increasing trend of short-stay hospitalizations in the elderly population [14]. No correlation with the increasing incidence of urolithiasis was made; however, the importance of these 2 findings is related to the fact that the average LoS in the emergency department is $20 \%$ longer in older adults compared to younger patients and the use of laboratory and radiology services is $50 \%$ higher, with a 4 -fold increase in need for social service input [14]. This has significant im- plications for those involved with the planning and provision of healthcare.

Our data demonstrate an increase in the number of FCEs for PCNL of 79\% between the years 2006/2007 and $2007 / 2008$. Care should be taken in the interpretation of this result. PCNL has only had its own OPCS-4 code (M16.4) since 2006 [5]; it is therefore likely that there was an under-representation of PCNL procedures within that year. Nevertheless, there has been an increase in the number of PCNLs performed between 2007/2008 and $2013 / 2014$ to the tune of $70 \%$. In contrast, a recent, regional, study in New Zealand demonstrated a decrease in PCNL procedures over a similar time period [15]. It is, however, possible that the number of PCNLs performed in England will continue to rise. Recent advances in the technologies associated with performing PCNL, including the use of mini-PCNL, ultramini-PCNL and microPCNL, have resulted in percutaneous access to kidney stones via a $4.8 \mathrm{~F}$ tract [16]. However, a recent systematic review and meta-analysis comparing PCNL (including mini-PCNL and micro-PCNL) advocated against the use of these new technologies pending further randomized studies [17]. It is therefore difficult to accurately predict the future of PCNL within England.

The cost of URS and lithotripsy has decreased and has become more cost-effective over the last few years with more centers performing it [18]. Nevertheless, with a rising trend of urolithiasis, primary prevention seems to be more cost-effective for a national healthcare system and contributes to a significant cost saving and reduction in stone burden to society [19].

Trends of Emergency Procedures for Urolithiasis

The number of ureteroscopic stone procedures within England has increased significantly over this study period with an associated increase in emergency ureteroscopic procedures. This is likely to be as a result of an increase in the availability of equipment, access to laser machines and semi-rigid ureteroscopes, as well as access to time in the emergency theatre over the study period. Furthermore, there is increasing data to support the utilization of emergency URS; recently, it has been found to be feasible, safe and effective with a success rate of $72 \%$ [20]. It is therefore likely that emergency URS rates will continue to increase relative to SWL.

Trends in Length of Hospital Stay

During the study period, the median LoS has demonstrated a decreasing trend. However, despite the advancements in PCNL technology, the median LoS has re-
394

Urol Int 2017;98:391-396

DOI: $10.1159 / 000449510$
Rukin/Siddiqui/Chedgy/Somani 
mained, constantly, at 4 days since $2007 / 2008$. With the aforementioned developments in PCNL technology and the increasing utilization of tubeless PCNL, this trend will hopefully fall. The increase in day-case URS, for both renal and ureteric stones, was significant but not unexpected given the increased sub-specialization among the urologists. Despite this, only $21-22 \%$ of ureteroscopic procedures are performed as a day-case. These proportions will hopefully increase over the next few years, especially as pressure on elective in-patient beds increase in the healthcare system.

\section{Strengths of Our Study}

As with all databases, the quality of output is commensurate with the quality of data that has been inputted. In the past, criticism has been leveled at HES data in terms of its accuracy as it relies largely upon coding data, recorded from patient notes, by non-clinicians in NHS hospitals, at the time of patient discharge [5]. Furthermore, a recent paper that investigated the accuracy of clinical coding for upper tract URS found that up to $55 \%$ of the coding data can be erroneous, with the particular error of renal URS being coded as ureteric URS [6]. In spite of this, a recent systematic review demonstrated a median accuracy of $84.2 \%$ for recorded procedure data within the HES database [7]. There is an increasing body of literature that interrogates HES data, with increasing degrees of complexity, to offer a 'real world' insight into patient outcomes rather than randomized controlled trials in specialized units [8]. HES data are also utilized by the Government to provide the basis for national indicators of clinical quality as well as to develop, monitor and evaluate government policy [9], and therefore, are seen to hold significant importance.

\section{Limitations of Our Study}

A limitation of the data available from HES is that only episodes of urolithiasis that required treatment by a hospital consultant are included in the database. The number of patients managed conservatively by their general practitioners cannot be captured with this data set. It is therefore likely that overall prevalence rates of urolithiasis within the UK are higher than those reported in this paper. Furthermore, it is interesting to note that the British Association of Urological Surgeons recently published, online, PCNL data from the whole of the UK for 2014 [10]. On an estimated capture of $90 \%$ of PCNL data, they recorded 2,042 procedures throughout the UK from January 2014 to December 2014. Looking more closely at this data, only 56 procedures were performed outside of England giving a total of 1986 PCNLs within England during that time period. This finding gives further rise to concern as to the absolute accuracy in data capture within the HES system. However, as the time periods studied between the 2 data sets are significantly disparate, it is difficult to make any meaningful conclusions between them.

\section{Conclusion}

The HES data presented here demonstrate the increasing prevalence and intervention of urolithiasis within England over the last 7 years. There is a rise in both elective and emergency urolithiasis interventions, with a rising trend for day-case URS. Similar trends are seen worldwide, and future resource planning for primary and secondary intervention for urolithiasis is needed to match the increase in demand.

\section{References}

1 Wong Y, Cook P, Roderick P, Somani BK: Metabolic syndrome and kidney stone disease: a systematic review of literature. J Endourol 2016;30:246-253

2 Turney BW, Reynard JM, Noble JG, Keoghane SR: Trends in urological stone disease. BJU Int 2012;109:1082-1087.

3 http://www.ons.gov.uk/peoplepopul ationand community/populationand migration/populationestimates/ (accessed July 2016)

4 http://www.ons.gov.uk/peoplepopulation andcommunity/birthsdeathsandmarriages/ lifeexpectancies/ (accessed July 2016).

5 Armitage JN, Withington J, van der Meulen J, Cromwell DA, Glass J, Finch WG, Irving SO,
Burgess NA: Percutaneous nephrolithotomy in England: practice and outcomes described in the hospital episode statistics database. BJU Int 2014;113:777-782.

6 Bedi N, Greenham OC, Inglis JA, Rukin NJ: Can an operative coding sticker improve remuneration for upper tract stone-related procedures. BJUI 2015;115:51.

7 Burns EM, Rigby E, Mamidanna R, Bottle A, Aylin P, Ziprin P, Faiz OD: Systematic review of discharge coding accuracy. J Public Health (oxf) 2012;34:138-148.

8 Sinha S, Peach G, Poloniecki JD, Thompson MM, Holt PJ: Studies using English administrative data (Hospital Episode Statistics) to assess health-care outcomes - systematic review and recommendations for reporting. Eur J Public Health 2013;23:86-92.

9 http://digital.nhs.uk/hes (accessed July 2016).

10 British Association of Urological Surgeons. 2015. http://www.baus.org.uk/patients/surgical outcomes/pcnl/ (accessed July 2016).

11 Ordon M, Urbach D, Mamdani M, Saskin R, Honey RJ, Pace KT: A population based study of the changing demographics of patients undergoing definitive treatment for kidney stone disease. J Urol 2015;193:869-874.

12 Ishii H, Couzins M, Aboumarzouk O, Biyani CS, Somani BK: Outcomes of systematic review of ureteroscopy for stone disease in the obese and morbidly obese population. J Endourol 2016;30:135-145. 
13 Ghani KR, Sammon JD, Karakiewicz PI, Sun M, Bhojani N, Sukumar S, Peabody JO, Menon M, Trinh QD: Trends in surgery for upper urinary tract calculi in the USA using the nationwide inpatient sample: 1999-2009. BJU Int 2013;112:224-230.

14 Greenwald PW, Stern ME, Rosen T, Clark S, Flomenbaum N: Trends in short-stay hospitalizations for older adults from 1990 to 2010: implications for geriatric emergency care. Am J Emerg Med 2014;32:311-314.
15 Acland G, Zargar-Shoshtari K, Rice M: Contemporary trends in urinary tract stone surgery, a regional perspective: Auckland, New Zealand. ANZ J Surg 2016;86:244-248.

16 Wells H, Rukin N, Wright A, Somani BK: Outcome-based comparison of percutaneous procedures for urinary lithiasis with calibre of instrumentation less than $12 \mathrm{Fr}$. Curr Urol Rep 2015;16:53.

17 De S, Autorino R, Kim FJ, Zargar H, Laydner $\mathrm{H}$, Balsamo R, Torricelli FC, Di Palma C, Molina WR, Monga M, De Sio M: Percutaneous nephrolithotomy versus retrograde intrarenal surgery: a systematic review and metaanalysis. Eur Urol 2015;67:125-137.
18 Somani BK, Robertson A, Kata SG: Decreasing the cost of flexible ureterorenoscopic procedures. Urology 2011;78:528-530.

19 Lotan Y, Buendia Jiménez I, Lenoir-Wijnkoop I, Daudon M, Molinier L, Tack I, Nuijten MJ: Primary prevention of nephrolithiasis is costeffective for a national healthcare system. BJU Int 2012;110(11 pt C):E1060-E1067.

20 Zargar-Shoshtari K, Anderson W, Rice M: Role of emergency ureteroscopy in the management of ureteric stones: analysis of 394 cases. BJU Int 2015;115:946-950. 